Acta Crystallographica Section B

Structural

Science

ISSN 0108-7681

\section{lain D. H. Oswald, \\ W. D. Samuel Motherwell ${ }^{b}$ and Simon Parsons ${ }^{\mathrm{a}}$}

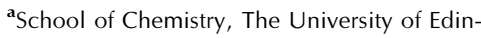
burgh, King's Buildings, West Mains Road, Edinburgh EH9 3JJ, Scotland, and ${ }^{\mathbf{b} C a m b r i d g e}$ Crystallographic Data Centre, 12 Union Road, Cambridge CB2 1EZ, England

Correspondence e-mail: i.d.h.oswald@sms.ed.ac.uk

\title{
Formation of quinol co-crystals with hydrogen-bond acceptors
}

The crystal structures of eight new co-crystals of quinol with pyrazine, piperazine, morpholine, pyridine, piperidine, 4,4'bipyridine, $N$-methylmorpholine and $N, N^{\prime}$-dimethylpiperazine are reported. Quinol forms 1:1 co-crystals with pyrazine, piperazine and $N, N^{\prime}$-dimethylpiperazine, but 1:2 co-crystals with morpholine, 4,4'-bipyridine, $N$-methylmorpholine, pyridine and piperidine. This difference can be rationalized in most cases by the presence of, respectively, two or one strong hydrogen-bond acceptor(s) in the guest molecule. The exception to this generalization is $4,4^{\prime}$-bipyridine, which forms a 1:2 co-crystal, possibly to optimize crystal packing. All structures are dominated by hydrogen bonding between quinol and the guest molecules. A doubly bridging motif, which connects pairs of quinol and guest molecules via $\mathrm{NH} \cdots \mathrm{O}$ or $\mathrm{CH} \cdots \mathrm{O}$ interactions, is present in all but the sterically hindered $N, N^{\prime}$-dimethylpiperazine and $N$-methylmorpholine co-crystals.

\section{Introduction}

Quinol, or hydroquinone, is widely used to stabilize compounds that are susceptible to polymerization. It has been shown to crystallize in three polymorphic forms. The structure of the $\alpha$-polymorph $(R \overline{3})$ was determined by Bolte \& Lerner (2001); the $\beta$-polymorph was determined by Lindeman et al. (1981) and found to belong to the same space group, but with a smaller cell $\left(Z^{\prime}=\frac{1}{2}\right.$ rather than $\left.Z^{\prime}=3\right)$. These two polymorphs were previously identified by Caspari $(1926,1927)$, but there was some ambiguity in the determination of the space group. The $\gamma$-polymorph was found to crystallize in space group $P 2_{1} / c$ (Maartmann-Moe, 1966).

Quinol shows a great propensity for co-crystallizing with a variety of different compounds. A search of the Cambridge Structural Database, Version 5.25 (CSD: Allen \& Motherwell, 2002) shows that there are 92 co-crystals of quinol with a range of organic compounds. Of all the structures in the database over half were co-crystals of quinol with hydrogen-bond acceptors, including 1,4-dioxane (Barnes et al., 1990). A previous paper by our group (Oswald et al., 2002) described how molecules analogous to dioxane yielded a series of crystal structures with closely related packing motifs, and in this paper we report the crystal structures of co-crystals of quinol with pyrazine, piperazine, morpholine, pyridine, piperidine and 4,4'-bipyridine (hereafter referred to as guest molecules). These all crystallize in a manner related to that of the dioxane co-crystal. The structures of the $N$-methylmorpholine and $N, N^{\prime}$-dimethylpiperazine co-crystals, which were also determined, highlight the effect of steric hindrance on the common
Received 21 June 2004

Accepted 6 November 2004
(C) 2005 International Union of Crystallography Printed in Great Britain - all rights reserved 
structural motifs present for the unsubstituted guest molecules. Fig. 1 shows all the guest molecules used in the series.

\section{Experimental}

\subsection{Synthesis}

All starting materials were obtained from Sigma-Aldrich and used as received.

2.1.1. Quinol-pyrazine (1/1) (1). Quinol (0.70 g, $6.36 \mathrm{mmol})$ was refluxed with pyrazine $(0.51 \mathrm{~g}, 6.38 \mathrm{mmol})$ in ethanol $\left(3 \mathrm{~cm}^{3}\right)$ until the solid dissolved. The solution was allowed to cool to room temperature to produce crystals as colourless blocks.

2.1.2. Quinol-piperazine (1/1) (2). Quinol (0.60 g, $5.45 \mathrm{mmol})$ was refluxed with piperazine $(0.50 \mathrm{~g}, 5.81 \mathrm{mmol})$ in ethanol $\left(3 \mathrm{~cm}^{3}\right)$ until the solid dissolved. The solution was allowed to cool to room temperature to produce crystals in the form of colourless blocks.

2.1.3. Quinol-morpholine (1/2) (3). Quinol (0.65 g, $5.90 \mathrm{mmol})$ was refluxed with morpholine $(0.53 \mathrm{~g}, 5.95 \mathrm{mmol})$ with a little ethanol until the solid dissolved. Colourless, crystalline blocks were obtained on cooling to $277 \mathrm{~K}$.

2.1.4. Quinol-pyridine (1/2) (4). Quinol (0.49 g, $4.45 \mathrm{mmol})$ was dissolved in an excess of pyridine and drawn into a glass capillary (o.d. $0.32 \mathrm{~mm}$ ). A polycrystalline sample was obtained on freezing the sample at $253 \mathrm{~K}$ and a crystal grown using the laser-assisted zone-refinement procedure of Boese \& Nussbaumer (1994).

2.1.5. Quinol-piperidine (1/2) (5). Quinol (0.49 g, $4.45 \mathrm{mmol}$ ) was refluxed in a minimum volume of piperidine to dissolve the solid. The solution was allowed to cool to room temperature to produce crystals as colourless blocks.

2.1.6. Quinol-bipyridine (1/2) (6). Quinol ( $0.59 \mathrm{~g}$, $5.84 \mathrm{mmol})$ was refluxed with $4,4^{\prime}$-bipyridine $(0.87 \mathrm{~g}$,<smiles>C1COCCO1</smiles><smiles>c1cnccn1</smiles>
1<smiles>c1cc(-c2ccncc2)ccn1</smiles><smiles>C1CNCCN1</smiles>

2<smiles>C1COCCN1</smiles>

3

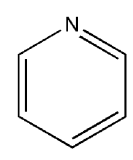

4<smiles>C1CCNCC1</smiles>

5<smiles>CN1CCOCC1</smiles><smiles>CN1CCN(C)CC1</smiles>

8

Figure 1

Guest molecules used to form co-crystals with quinol. From left to right the structures show: top: dioxane, pyrazine, piperazine, morpholine, pyridine; bottom: piperidine, 4,4'-bipyridine, $N$-methylmorpholine and $N, N$-dimethylpiperazine. The structure numbers, (1)-(8) refer to the adducts that these molecules form with quinol.

$5.58 \mathrm{mmol}$ ) in $3 \mathrm{~cm}^{3}$ of ethanol until the solid dissolved. The solution was allowed to cool to room temperature to produce colourless laths. An attempt was made to prepare a 1:1 adduct using the method employed by Corradi et al. (2000): quinol $(0.53 \mathrm{~g}, 4.82 \mathrm{mmol})$ and 4,4'-bipyridine $(0.80 \mathrm{~g}, 5.13 \mathrm{mmol})$ were dissolved in hot acetone $\left(40 \mathrm{~cm}^{3}\right)$, and the mixture allowed to cool to room temperature. The colourless crystals were identified as (6) from their unit-cell dimensions.

2.1.7. Quinol-N-methylmorpholine (1/2) (7). Quinol $(0.55 \mathrm{~g}, 5.00 \mathrm{mmol})$ was dissolved in $\mathrm{N}$-methylmorpholine $(1.00 \mathrm{~g}, 10.30 \mathrm{mmol})$ and drawn into a glass capillary (o.d. $0.38 \mathrm{~mm}$ ). A crystal was grown at $240 \mathrm{~K}$ from a polycrystalline sample of the frozen liquid by Boese's method (see above).

2.1.8. Quinol- $N, N^{\prime}$-dimethylpiperazine (1/1) (8). Quinol $(0.65 \mathrm{~g}, 5.90 \mathrm{mmol})$ was refluxed with dimethylpiperazine $\left(3 \mathrm{~cm}^{3}, 20.10 \mathrm{mmol}\right)$ in a little ethanol until the solid dissolved. The solution was held at $277 \mathrm{~K}$ to produce colourless crystalline blocks.

\subsection{Crystallography}

X-ray diffraction intensities were collected with Mo $K \alpha$ radiation on a Bruker SMART APEX CCD diffractometer equipped with an Oxford Cryosystems low-temperature device (Cosier \& Glazer, 1986). Absorption corrections were carried out using the multiscan procedure SADABS (Sheldrick, 1997a; based on the procedure described by Blessing, 1995). All structures were solved by direct methods and refined by full-matrix least-squares against $F^{2}$ using all data (SHELXTL; Sheldrick, 1997b). H atoms were placed on C atoms in calculated positions and allowed to ride on their parent atoms. Methyl groups were treated with the Sheldrick (1997b) rotating rigid-group model, except one methyl group in the dimethylpiperazine co-crystal which exhibited high thermal motion or some disorder (not modelled), where the positions were calculated purely on stereochemical grounds. $\mathrm{H}$ atoms involved in hydrogen bonding were located in difference maps and refined freely. All non-H atoms were modelled with anisotropic displacement parameters.

The diffraction pattern of the piperazine co-crystal indexed readily on the cell with $a=7.1977$ (18), $b=8.859$ (2), $c=$ 13.247 (4) $\AA, \alpha=80.420$ (6), $\beta=74.400$ (4), $\gamma=66.153$ (4) ${ }^{\circ}$. This can be transformed to a pseudo-monoclinic C-centred cell, although the Laue symmetry was clearly $\overline{1}$ and not $2 / \mathrm{m}$. While the structure solved and refined without difficulty, it appeared to be twinned by a twofold rotation about [100] - the pseudomonoclinic $b$ axis. The $R$ factor was 0.06 , and bond distances and angles were normal. Symmetry checking (PLATON; Spek, 2002) implied that the structure could be described using a smaller unit cell and closer inspection of the intensities revealed that data with $k+l=3 n$ had an average $I / \sigma(I)$ some eight times larger than the rest of the data. [This could also be readily recognized in the Patterson function, which had a peak with a height of about two-thirds that of the origin peak at approximately $(0,1 / 3,1 / 3)$.] The data set was transformed using the matrix 
Table 1

Crystallographic data for the co-crystals of quinol with pyrazine, piperazine, morpholine, pyridine, piperidine, $4,4^{\prime}$-bipyridine, $N$-methylmorpholine and $N, N^{\prime}$-dimethylpiperazine.

All data were collected at $150 \mathrm{~K}$.

(1)

$\mathrm{C}_{6} \mathrm{H}_{6} \mathrm{O}_{2} \cdot \mathrm{C}_{4} \mathrm{H}_{4} \mathrm{~N}_{2}$ 190.20

Chemical formula

$M_{r}$

Cell setting, space group

$a, b, c(\AA)$

$\alpha, \beta, \gamma\left(^{\circ}\right)$

$V\left(\AA^{3}\right)$

Z

$D_{x}\left(\mathrm{Mg} \mathrm{m}^{-3}\right)$

Radiation type

No. of reflections for cell parameters

$\theta$ range $\left(^{\circ}\right.$ )

$\mu\left(\mathrm{mm}^{-1}\right)$

Temperature (K)

Crystal form, colour

Crystal size (mm)

Data collection

Diffractometer

Data collection method

Absorption correction

$T_{\min }$

$T_{\max }$
No. of measured, indepen-

dent and observed

reflections

Criterion for observed reflections

$R_{\text {int }}$

$\theta_{\max }\left({ }^{\circ}\right)$

Range of $h, k, l$

Refinement

Refinement on

$R\left[F^{2}>2 \sigma\left(F^{2}\right)\right], w R\left(F^{2}\right), S$

No. of reflections

No. of parameters

$\mathrm{H}$-atom treatment

Weighting scheme

$(\Delta / \sigma)_{\max }$

$\Delta \rho_{\max }, \Delta \rho_{\min }\left(\mathrm{e}^{-3}\right)$

Extinction method

476.6 (3)

2

1.325

Mo $K \alpha$

834

2.3-26.7

0.10

150 (2)

Plate, colourless

$\omega$ scans

Multi-scan

0.787

1

2873, 1141, 926

$I>2 \sigma(I)$

0.023

28.8

$-10 \Rightarrow h \Rightarrow 11$

$-9 \Rightarrow k \Rightarrow 10$

$-8 \Rightarrow l \Rightarrow 9$

$F^{2}$

$0.047,0.115,1.07$

1141

68 $\left.2 F_{c}^{2}\right) / 3$

$<0.0001$

$0.26,-0.30$

None

(2)

(3)

\section{$\mathrm{C}_{4} \mathrm{H}_{10} \mathrm{~N}_{2} \cdot \mathrm{C}_{6} \mathrm{H}_{6} \mathrm{O}_{2}$}

196.25

Monoclinic, $P 2_{1} / c$

8.901 (3), 7.666 (2), 6.984 (2)

$90.00,90.091$ (6), 90.00

$0.39 \times 0.28 \times 0.10$

CCD area detector

Mixture of independent and constrained refinement

$w=1 /\left[\sigma^{2}\left(F_{o}^{2}\right)+(0.0544 P)^{2}+\right.$ $0.1051 P]$, where $P=\left(F_{o}^{2}+\right.$
Triclinic twin, $P \overline{1}$

5.7060 (15), 6.7599 (19),

7.0771 (18)

100.269 (4), 112.446 (3),

$90.163(3)$

247.50 (11)

1.317

Mo $K \alpha$

2430

3.1-28.7

0.09

150 (2)

Block, colourless

$0.27 \times 0.23 \times 0.06$

CCD area detector

$\omega$ scans

Multi-scan

0.874

3814, 1194, 1117

$I>2 \sigma(I)$

0.029

28.8

$-7 \Rightarrow h \Rightarrow 7$

$-9 \Rightarrow k \Rightarrow 8$

$-9 \Rightarrow l \Rightarrow 9$

$F^{2}$

0.051, 0.118, 1.09

1194

73

Mixture of independent and constrained refinement

$w=1 /\left[\sigma^{2}\left(F_{o}^{2}\right)+(0.0269 P)^{2}+\right.$ $0.1505 P]$, where $P=\left(F_{o}^{2}+\right.$ $\left.2 F_{c}^{2}\right) / 3$

$<0.0001$

$0.32,-0.33$

None

\section{$2 \mathrm{C}_{4} \mathrm{H}_{9} \mathrm{NO} \cdot \mathrm{C}_{6} \mathrm{H}_{6} \mathrm{O}_{2}$ \\ 284.36 \\ Monoclinic, $P 2_{1} / n$ \\ 6.6652 (13), 5.5881 (11), \\ 20.034 (4) \\ 90.00, 94.942 (4), 90.00}

743.4 (3)

1.270

Mo $K \alpha$

1472

$3.3-28.3$

0.09

150 (2)

Block, colourless

$0.31 \times 0.22 \times 0.09$

CCD area detector

$\omega$ scans

Multi-scan

0.675

4226, 1730, 1427

$I>2 \sigma(I)$

0.038

28.5

$-8 \Rightarrow h \Rightarrow 8$

$-7 \Rightarrow k \Rightarrow 6$

$-26 \Rightarrow l \Rightarrow 19$

$F^{2}$

$0.085,0.211,1.18$

1730

99

Mixture of independent and constrained refinement

$w=1 /\left[\sigma^{2}\left(F_{o}^{2}\right)+(0.0914 P)^{2}+\right.$ $0.6423 P]$, where $P=\left(F_{o}^{2}+\right.$

$\left.2 F_{c}^{2}\right) / 3$

$<0.0001$

$0.44,-0.30$

None
(4)

\section{$\mathrm{C}_{3} \mathrm{H}_{3} \mathrm{O} \cdot \mathrm{C}_{5} \mathrm{H}_{5} \mathrm{~N}$}

268.31

Monoclinic, $P 2_{1} / c$

6.4990 (9), 16.459 (2),

7.1794 (10)

90.00, 112.986 (3), 90.00

707.00 (17)

1.260

Mo $K \alpha$

1519

2.4-28.5

0.08

150 (2)

Cylinder, colourless

$1 \times 0.32 \times 0.32$

CCD area detector

$\omega$ scans

Multi-scan

0.593

5091, 1700, 1345

$I>2 \sigma(I)$

0.031

28.9

$-8 \Rightarrow h \Rightarrow 7$

$-21 \Rightarrow k \Rightarrow 21$

$-8 \Rightarrow l \Rightarrow 9$

$F^{2}$

$0.083,0.172,1.33$

1700

95

Mixture of independent and constrained refinement

$w=1 /\left[\sigma^{2}\left(F_{o}^{2}\right)+(0.0363 P)^{2}+\right.$ $0.5217 P]$, where $P=\left(F_{o}^{2}+\right.$ $\left.2 F_{c}^{2}\right) / 3$

$<0.0001$

$0.28,-0.39$

None

\section{(5)}

(6)

(7)

(8)

Crystal data

Chemical formula

$2 \mathrm{C}_{5} \mathrm{H}_{11} \mathrm{~N} \cdot \mathrm{C}_{6} \mathrm{H}_{6} \mathrm{O}_{2}$

$M_{r}$

280.40

Monoclinic, $P 2_{1} / c$

10.4230 (15), 5.2619 (7),

$15.221(2)$

$a, b, c(\AA)$

$\alpha, \beta, \gamma\left(^{\circ}\right)$

90.00, 109.920 (3), 90.00

$V\left(\AA^{3}\right)$

$D_{x}\left(\mathrm{Mg} \mathrm{m}^{-3}\right)$

784.84 (19)

Radiation type

No. of reflections for cell

2

1.187

Mo $K \alpha$

774

$2 \mathrm{C}_{10} \mathrm{H}_{8} \mathrm{~N}_{2} \cdot \mathrm{C}_{6} \mathrm{H}_{6} \mathrm{O}_{2}$

422.49

Triclinic, $P \overline{1}$

7.820 (4), 8.619 (4), 9.201 (4)

\section{$2 \mathrm{C}_{5} \mathrm{H}$}

Triclinic, $P$

6.9612 (10), 7.3146 (11),

9.659 (2)

111.897 (7), 109.851 (7),

$94.657(8)$

525.7 (4)

1

1.335

Mo $K \alpha$

2247
106.182 (3), 104.481 (3),

106.201 (2)

423.94 (12)

1

1.224

Mo $K \alpha$

2797
$\mathrm{C}_{6} \mathrm{H}_{14} \mathrm{~N}_{2} \cdot \mathrm{C}_{6} \mathrm{H}_{6} \mathrm{O}_{2}$

224.30

Triclinic, $P$

8.9620 (8), 9.4944 (8),

14.7119 (13)

90.501 (2), 92.919 (2),

99.664 (2)

1232.26 (19)

4

1.209

Mo $K \alpha$

1812 parameters 
Table 1 (continued)

\begin{tabular}{|c|c|c|c|c|}
\hline & $(5)$ & $(6)$ & (7) & (8) \\
\hline$\theta$ range $\left({ }^{\circ}\right)$ & $2.9-25.3$ & $2.6-28.4$ & $2.4-28.8$ & $2.6-24.4$ \\
\hline$\mu\left(\mathrm{mm}^{-1}\right)$ & 0.08 & 0.09 & 0.09 & 0.08 \\
\hline Temperature (K) & $150(2)$ & $150(2)$ & $150(2)$ & $150(2)$ \\
\hline Crystal form, colour & Block, colourless & Lath, colourless & Cylinder, colourless & Block, colourless \\
\hline Crystal size (mm) & $0.33 \times 0.18 \times 0.18$ & $0.77 \times 0.22 \times 0.15$ & $1 \times 0.38 \times 0.38$ & $0.34 \times 0.20 \times 0.11$ \\
\hline \multicolumn{5}{|l|}{ Data collection } \\
\hline Diffractometer & $\mathrm{CCD}$ area detector & $\mathrm{CCD}$ area detector & CCD area detector & CCD area detector \\
\hline Data collection method & $\omega$ scans & $\omega$ scans & $\omega$ scans & $\omega$ scans \\
\hline Absorption correction & Multi-scan & Multi-scan & Multi-scan & Multi-scan \\
\hline$T_{\min }$ & 0.661 & 0.763 & 0.774 & 0.898 \\
\hline$T_{\max }$ & 1 & 1 & 1 & 1 \\
\hline $\begin{array}{l}\text { No. of measured, indepen- } \\
\text { dent and observed } \\
\text { reflections }\end{array}$ & $4754,1896,1327$ & $4641,2428,2067$ & $3788,1972,1794$ & $11345,5844,3873$ \\
\hline $\begin{array}{l}\text { Criterion for observed } \\
\text { reflections }\end{array}$ & $I>2 \sigma(I)$ & $I>2 \sigma(I)$ & $I>2 \sigma(I)$ & $I>2 \sigma(I)$ \\
\hline$R_{\text {int }}$ & 0.028 & 0.031 & 0.020 & 0.039 \\
\hline$\theta_{\max }\left({ }^{\circ}\right)$ & 29.0 & 28.7 & 28.8 & 28.9 \\
\hline Range of $h, k, l$ & $-14 \Rightarrow h \Rightarrow 7$ & $-10 \Rightarrow h \Rightarrow 10$ & $-9 \Rightarrow h \Rightarrow 9$ & $-12 \Rightarrow h \Rightarrow 12$ \\
\hline & $-7 \Rightarrow k \Rightarrow 7$ & $-11 \Rightarrow k \Rightarrow 11$ & $-9 \Rightarrow k \Rightarrow 9$ & $-12 \Rightarrow k \Rightarrow 12$ \\
\hline & $-17 \Rightarrow l \Rightarrow 19$ & $-12 \Rightarrow l \Rightarrow 12$ & $-12 \Rightarrow l \Rightarrow 13$ & $-19 \Rightarrow l \Rightarrow 19$ \\
\hline \multicolumn{5}{|l|}{ Refinement } \\
\hline Refinement on & $F^{2}$ & $F^{2}$ & $F^{2}$ & $F^{2}$ \\
\hline$R\left[F^{2}>2 \sigma\left(F^{2}\right)\right], w R\left(F^{2}\right), S$ & $0.056,0.136,1.04$ & $0.054,0.144,1.04$ & $0.045,0.120,1.07$ & $0.074,0.162,1.03$ \\
\hline No. of reflections & 1896 & 2428 & 1972 & 5844 \\
\hline No. of parameters & 99 & 150 & 106 & 308 \\
\hline $\mathrm{H}$-atom treatment & $\begin{array}{l}\text { Mixture of independent and } \\
\text { constrained refinement }\end{array}$ & $\begin{array}{l}\text { Mixture of independent and } \\
\text { constrained refinement }\end{array}$ & $\begin{array}{l}\text { Mixture of independent and } \\
\text { constrained refinement }\end{array}$ & $\begin{array}{l}\text { Mixture of independent and } \\
\text { constrained refinement }\end{array}$ \\
\hline Weighting scheme & $\begin{array}{l}w=1 /\left[\sigma^{2}\left(F_{o}^{2}\right)+(0.0582 P)^{2}+\right. \\
\quad 0.1207 P], \text { where } P=\left(F_{o}^{2}+\right. \\
\left.\quad 2 F_{c}^{2}\right) / 3\end{array}$ & $\begin{array}{l}w=1 /\left[\sigma^{2}\left(F_{o}^{2}\right)+(0.0803 P)^{2}+\right. \\
\quad 0.1067 P], \text { where } P=\left(F_{o}^{2}+\right. \\
\left.\quad 2 F_{c}^{2}\right) / 3\end{array}$ & $\begin{array}{l}w=1 /\left[\sigma^{2}\left(F_{o}^{2}\right)+(0.063 P)^{2}+\right. \\
\quad 0.0864 P], \text { where } P=\left(F_{o}^{2}+\right. \\
\left.\quad 2 F_{c}^{2}\right) / 3\end{array}$ & $\begin{array}{l}w=1 /\left[\sigma^{2}\left(F_{o}^{2}\right)+(0.0536 P)^{2}+\right. \\
\quad 0.587 P], \text { where } P=\left(F_{o}^{2}+\right. \\
\left.\quad 2 F_{c}^{2}\right) / 3\end{array}$ \\
\hline$(\Delta / \sigma)_{\max }$ & $<0.0001$ & $<0.0001$ & $<0.0001$ & $<0.0001$ \\
\hline$\Delta \rho_{\max }, \Delta \rho_{\min }\left(\mathrm{e} \AA^{-3}\right)$ & $0.24,-0.19$ & $0.31,-0.26$ & $0.24,-0.26$ & $0.50,-0.43$ \\
\hline Extinction method & None & SHELXL & SHELXL & None \\
\hline Extinction coefficient & - & $0.013(9)$ & $0.29(4)$ & - \\
\hline
\end{tabular}

Computer programs used: Bruker SMART, Bruker SHELXTL, SHELXS97 (Sheldrick, 1997b), SHELXL97 (Sheldrick, $1997 b)$.

$$
\left(\begin{array}{ccc}
0 & \frac{1}{3} & \frac{1}{3} \\
0 & -\frac{2}{3} & \frac{1}{3} \\
1 & -\frac{1}{3} & -\frac{1}{3}
\end{array}\right),
$$

and refined using a twofold rotation about [101], which corresponds to the matrix

$$
\left(\begin{array}{ccc}
-\frac{1}{3} & 0 & \frac{2}{3} \\
-\frac{1}{3} & -1 & -\frac{1}{3} \\
\frac{4}{3} & 0 & \frac{1}{3}
\end{array}\right) .
$$

Reflections where $h+l=3 n$ contain contributions from both twin domains; the twin scale factor was 0.1185 (16).

A consistent numbering scheme was used for the quinol molecules in all structures and this is shown in the following scheme. Where there is more than one quinol molecule in the asymmetric unit the labels shown are augmented with the letters $A$ and $B$. Labels for atoms forming part of the guest molecules carry the letters $S, T$ etc. A full listing of crystal, data collection and refinement parameters is given in Table $1^{\mathbf{1}}$ and a set of hydrogen-bonding parameters is given in Table 2.

\footnotetext{
1 Supplementary data for this paper are available from the IUCr electronic archives (Reference: WS5013). Services for accessing these data are described at the back of the journal.
}

Structures were visualized using SHELXTL or MERCURY (Taylor \& Macrae, 2001; Bruno et al., 2002); the figures were produced using CAMERON (Watkin et al., 1993). Other analyses utilized the p.c. version of the program PLATON (Spek, 2002; Farrugia, 1999). Searches of the Cambridge Crystallographic Database (Allen \& Motherwell, 2002) were carried out with the program CONQUEST, utilizing Version 5.25 of the database. Graph-set assignments were confirmed using the GSET routine in RPLUTO (Motherwell et al., 1999).<smiles></smiles>

\section{Results}

\subsection{Quinol-dioxane (1/1)}

The structure of the quinol-dioxane co-crystal has been determined by Barnes et al. (1990; CSD Refcode SENJOK). In this paper we report co-crystals of quinol with several 
Table 2

Table of hydrogen-bonding parameters $\mathrm{C}-\mathrm{H}, \mathrm{N}-\mathrm{H}$ and $\mathrm{O}-\mathrm{H}$ distances were normalized to $1.083,1.009$ and $0.983 \AA$, respectively, to aid comparison with Cambridge Database search results (Table 3).

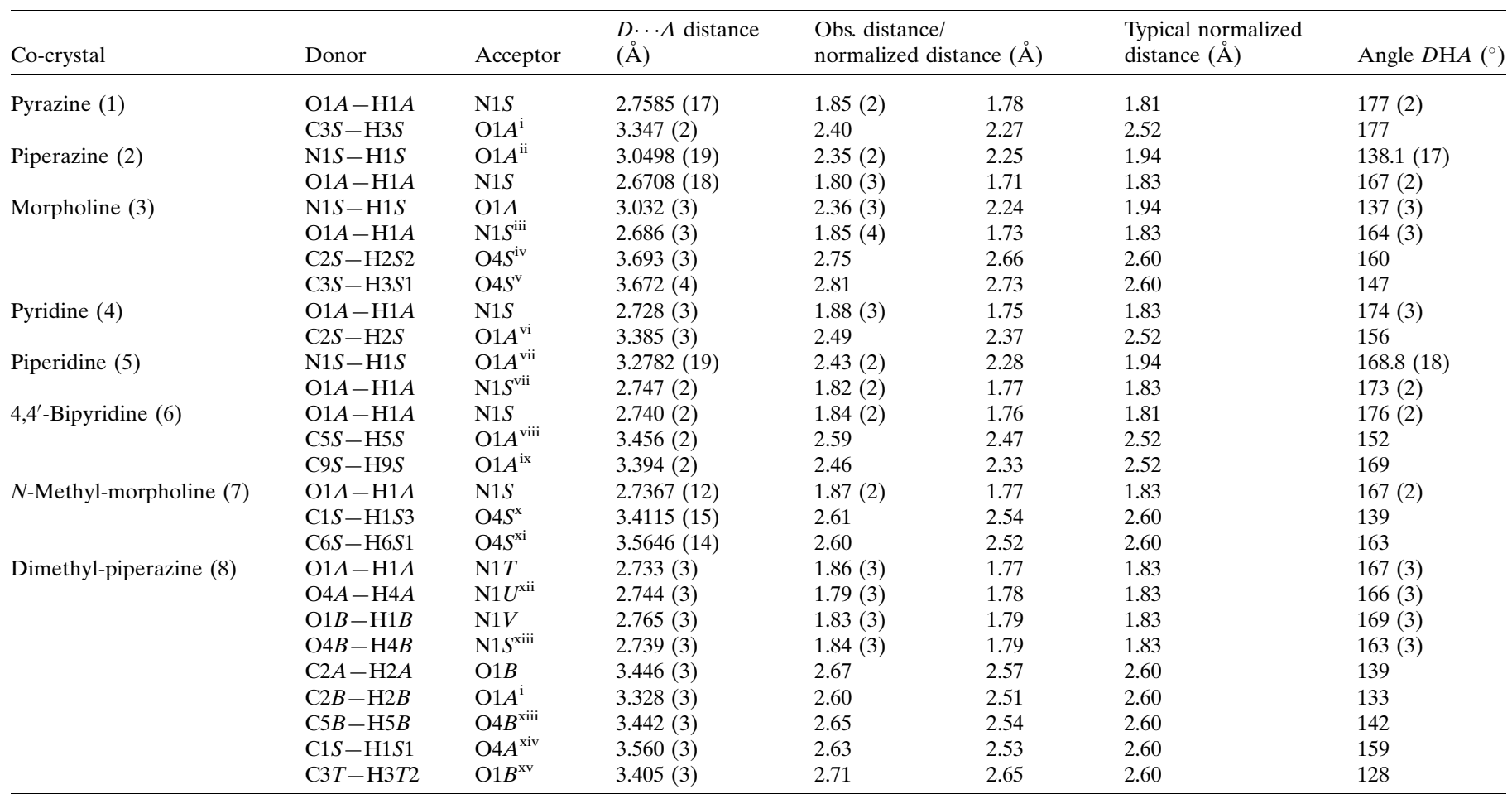

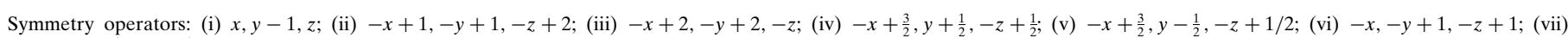

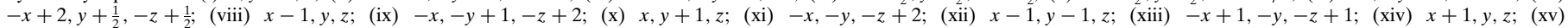
$-x+1,-y+1,-z$.

compounds which are related to dioxane by their hydrogenbonding properties; we discuss the structure of the quinoldioxane co-crystal here in order to be able to make comparisons with the co-crystals that form the subject of the rest of this paper.

The asymmetric unit of quinol-dioxane (space group $P 2_{1} / a$ ) consists of half-molecules of each component. The primary hydrogen-bonding motif in the structure is a $C_{2}^{2}(12)$ (Bernstein et al., 1995) chain formed by $\mathrm{O}-\mathrm{H} \cdots \mathrm{O}($ ether) hydrogen bonds which connect alternating quinol and dioxane molecules; these chains run from the top left to the lower right in Fig. 2. The chains are staggered, which allows the acceptor functionality of the hydroxyl to be filled by a close contact with a $\mathrm{C}-\mathrm{H}$ moiety of a dioxane molecule in a neighbouring chain $(\mathrm{CH}$ - . O $2.60 \AA$; the sum of the van der Waals radii of $\mathrm{H}$ and $\mathrm{O}$ is $2.72 \AA$ ). Interactions of this type link the chains together into a layer. $\mathrm{CH}$. . O interactions of similar dimensions are observed in both phases of dioxane (Buschmann et al., 1986) and in morpholine (Parkin et al., 2004).

A doubly bridging subunit composed of two quinol molecules and two dioxane molecules is presented in Fig. 2. Each quinol is hydrogen bonded to one of the dioxane molecules, but it also accepts a $\mathrm{CH}$. . O interaction from the second. At this level of graph-set analysis there are four donors consisting of pairs of $\mathrm{OH}$ and $\mathrm{CH}$ moieties, and four acceptors formed by pairs of ether and phenol $\mathrm{O}$ atoms. It is useful for the purposes of drawing comparisons with the other structures in this series to highlight this secondary level, $R_{4}^{4}(10)$ ring motif in which two quinol molecules are doubly bridged by two dioxane molecules.

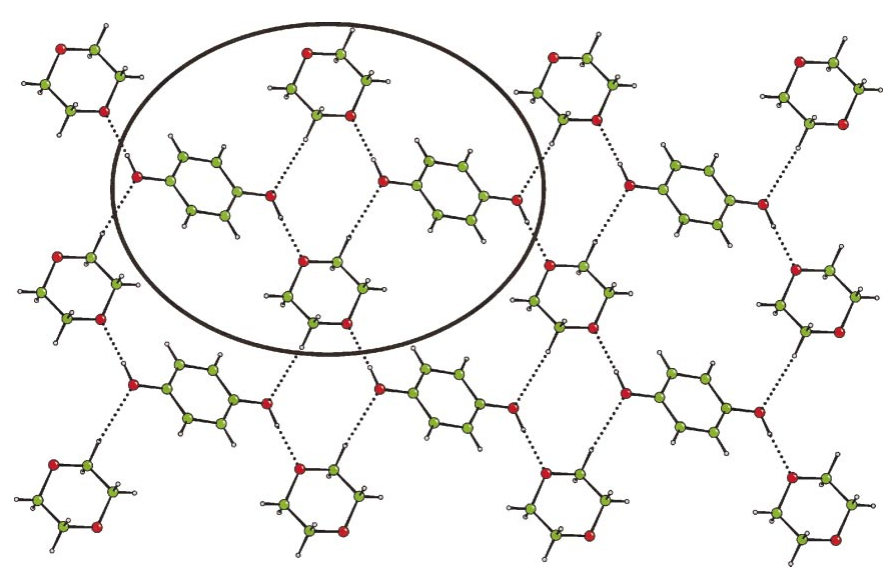

Figure 2

Quinol-dioxane (1/1) (CSD refcode: SENJOK) viewed perpendicular to the (100) planes. Colour scheme: $\mathrm{C}$ green, $\mathrm{H}$ grey and $\mathrm{O}$ red. The bridging motif through $\mathrm{OH}$... $\mathrm{O}$ interactions and a close contact between a $\mathrm{CH}$ and the $\mathrm{O}$ of the hydroxyl group gives a $R_{4}^{4}(10)$ graph set (circled). The layers occupy the (200) planes in the structure, and alternate layers have chains running along the [011] and [011] directions. 
Table 3

Summary of the results of searches of the CSD (Version 5.25, November 2003) for typical distances in hydrogen-bonded systems containing identical functional groups to the quinol co-crystals studied.

The distances to $\mathrm{H}$ atoms were normalized to typical neutron distances $(\mathrm{C}-\mathrm{H} 1.083, \mathrm{~N}-\mathrm{H} 1.009$ and $\mathrm{O}-\mathrm{H} 0.983 \AA$ ). Only 'organic' structures where the $R$ factor is less than 0.05 , with no errors or disorder, were included, and ionic or polymeric structures were excluded. The $\mathrm{C}$ atoms attached to the amine moieties were specified to be $s p^{2}$ or $s p^{3}$ hybridized. The donor-H-acceptor distance was specified to be 1.50-2.20 or 1.50-2.75 $\AA$ in the case of the CH donor atoms.

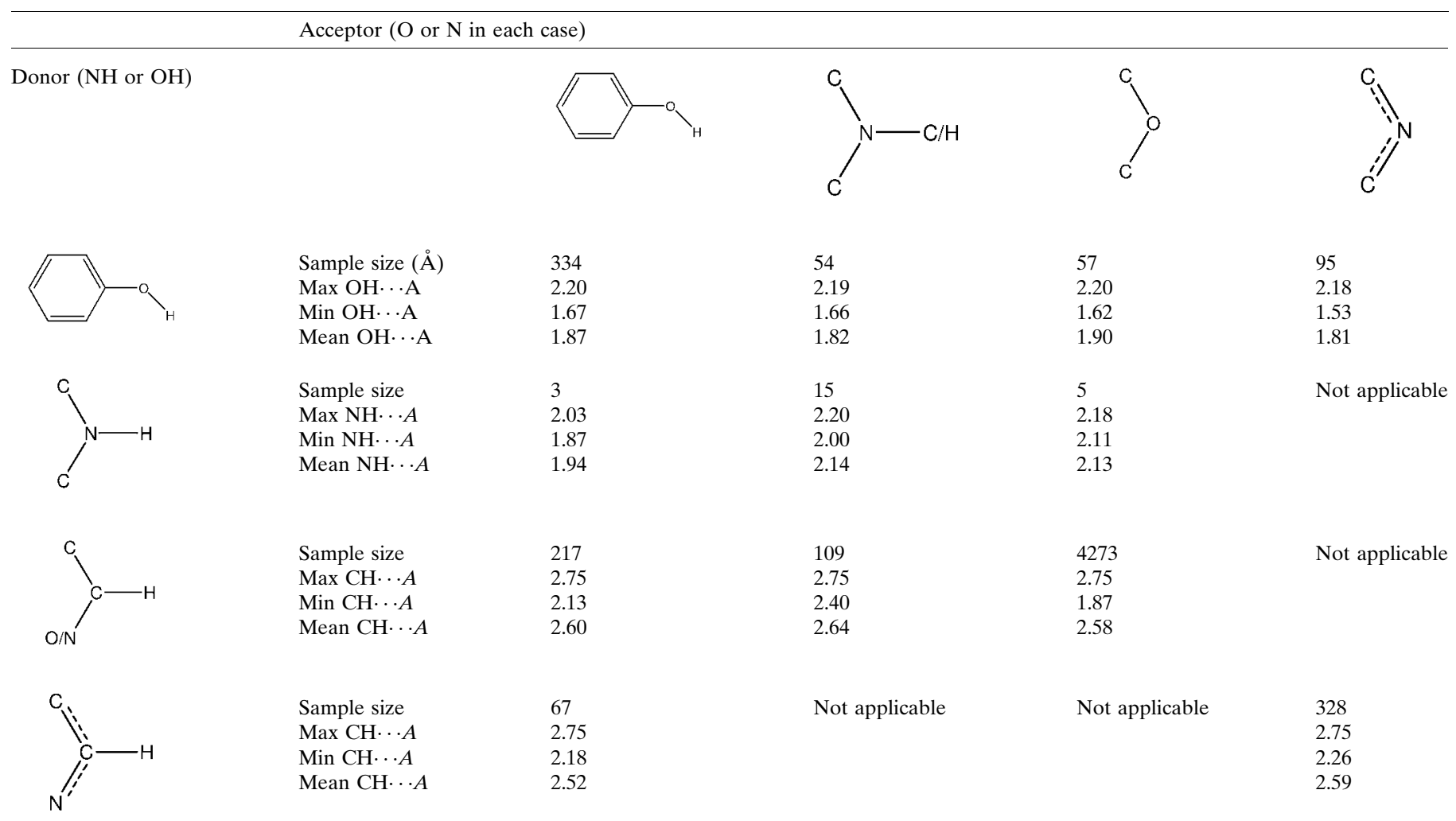

\subsection{Quinol-pyrazine (1/1) (1)}

Although pyrazine is chemically rather different to dioxane, the two molecules are similar in that they both consist of sixmembered rings with centrosymmetrically related hydrogenbond acceptors in the 1 and 4 positions. In addition, although ether oxygen can potentially act as a double acceptor, it rarely does so, and so the $\mathrm{N}$ atoms in pyrazine and the $\mathrm{O}$ atoms in dioxane can both be considered to be monofunctional hydrogen-bond acceptors.

The asymmetric unit of quinol-pyrazine (1/1) contains halfmolecules of quinol and pyrazine, both occupying inversion centres in the space group $P 2_{1} / c$. The primary bond distances and angles are normal for this and all the other structures reported here, and they are listed in the supplementary data. The structure is very similar to that of the dioxane co-crystal and the primary graph set consists of a $C_{2}^{2}(12)$ chain formed by alternating quinol and pyrazine molecules, which are hydrogen-bonded via $\mathrm{OH} \cdots \mathrm{N}$ interactions [H.N 1.85 (2) $\AA$, see Table 2]; the chains run from the top left to the lower right in Fig. 3. The orientation of pyrazine enables a close contact to be formed between a $\mathrm{C}-\mathrm{H}$ and the $\mathrm{O}$ of the hydroxyl group (2.40 $\AA$ ), which serves to link chains to form a layer. Thus, an

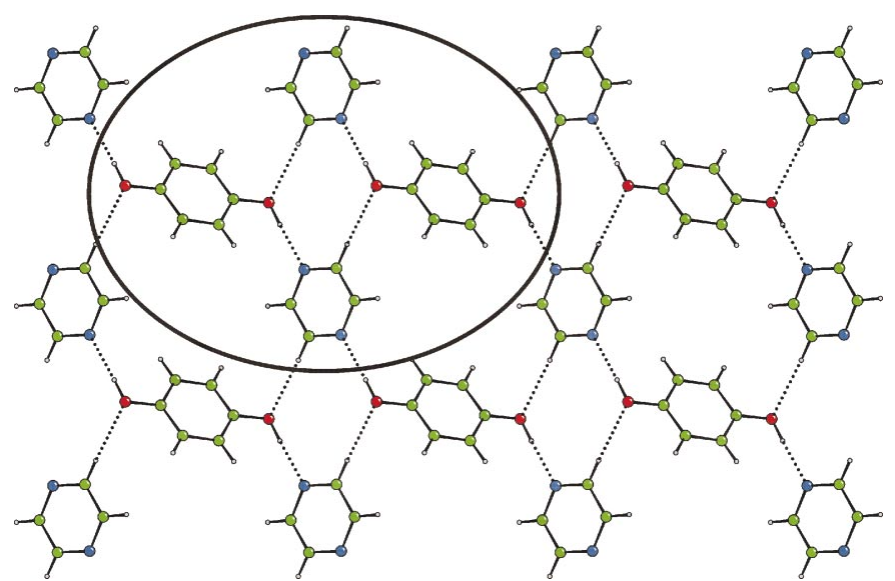

Figure 3

Quinol-pyrazine (1/1) (1) viewed perpendicular to the (001) planes. Colour scheme: $\mathrm{C}$ green, $\mathrm{H}$ grey, $\mathrm{O}$ red and $\mathrm{N}$ blue. A similar doubly bridging motif to the dioxane structure is observed (circled). The layers occupy the (002)_planes, and alternate layers contain chains passing along the [110] and [110] directions (note that the source of the differences in Miller indices between the dioxane and this pyrazine co-crystals is that the former has published coordinates referred to $P 2_{1} / a$, while the latter is in $P 2_{1} / c$ ). 
$R_{4}^{4}(10)$ subunit (Fig. 3) composed of two quinol molecules doubly bridged by two guest molecules, which characterized the dioxane co-crystal, is also observed here.

\subsection{Quinol-piperazine (1/1) (2)}

In quinol-piperazine (1/1) both components are located on inversion centres. The amine $\mathrm{H}$ atom (the position of which was derived from a difference-Fourier map) favours the axial position in the piperazine molecule. The structure is depicted in Fig. 4.

Piperazine is related to dioxane by the substitution of two $\mathrm{NH}$ groups for the ether $\mathrm{O}$ atoms. As in dioxane and pyrazine the $\mathrm{N}$ atoms act as monofunctional hydrogen-bond acceptors, but they can, in addition, act as hydrogen-bond donors. $C_{2}^{2}(12)$ chains are formed via $\mathrm{OH} \cdots \mathrm{N}$ hydrogen bonds and run from top left to lower right in Fig. 4. NH ..O hydrogen bonds are formed between the quinol and piperazine molecules in neighbouring chains, forming layers. The doubly bridging subunit (Fig. 4), which was observed in the dioxane and pyrazine co-crystals, is also observed here, although it forms an $R_{4}^{4}(8)$ graph, rather than $R_{4}^{4}(10)$, because the donor capacity of piperazine is 'built into' the amine group.

\subsection{Quinol-morpholine (1/2) (3)}

Morpholine is related to dioxane through the substitution of one of the $\mathrm{O}$ atoms with protonated nitrogen. This co-crystal crystallizes with one molecule of morpholine and half a molecule of quinol in the asymmetric unit, and in this respect it differs from the dioxane, pyrazine and piperazine co-crystals which all have 1:1 stoichometry. The quinol resides on a crystallographic inversion centre. The $\mathrm{H}$ atom (H1S) attached to the $\mathrm{N}$ atom in the morpholine molecule was located in a difference-Fourier map and found to occupy the less favourable axial position.

The hydrogen-bonding functionality of the quinol molecules, which form $\mathrm{OH} \cdots \mathrm{N}$ hydrogen bonds to the morpholine molecules, resembles that in the piperazine co-crystal. However, the ether $\mathrm{O}$ atoms do not participate in hydrogen

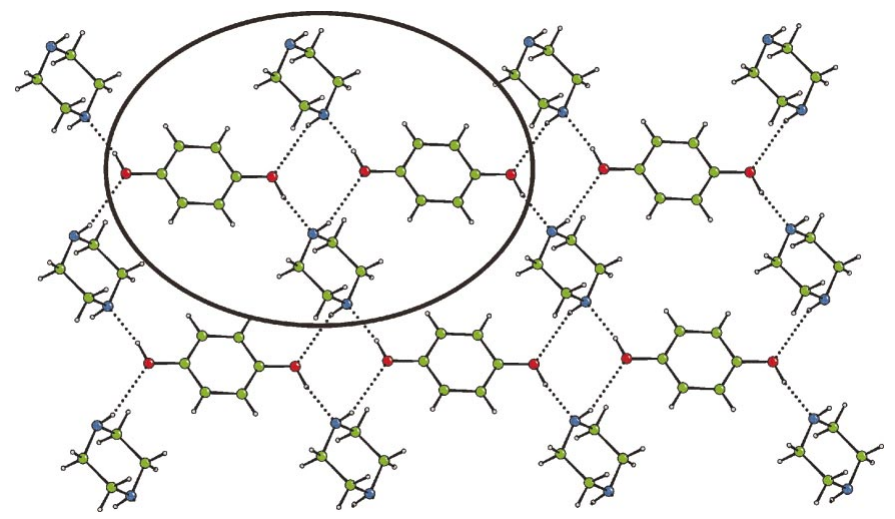

Figure 4

Quinol-piperazine (1/1) (2) viewed perpendicular to the (110) planes. The donor-acceptor function of the amine moiety allows the co-crystal to form an $R_{4}^{4}(8)$ hydrogen-bonded doubly bridging motif (circled). bonding and the $C_{2}^{2}(12)$ chain motif observed in the piperazine co-crystal corresponds to a discrete $D_{2}^{2}(10)$ motif consisting of one quinol and two morpholine molecules in this co-crystal (see Fig. $5 a$ running diagonally from top left to lower right): the ether $\mathrm{O}$ atoms act like chain-stoppers. Neighbouring quinol-morpholine (1/2) units are linked by $\mathrm{NH} \cdots \mathrm{O}$ hydrogen-bonding interactions. A doubly bridging subunit (Fig. 5a) analogous to those observed in the structures described above therefore also appears in this co-crystal. As in the piperazine co-crystal its secondary level graph-set descriptor is $R_{4}^{4}(8)$.

The ether $\mathrm{O}$ atom does not participate in any interactions which would be considered significant using a criterion based on the sums of the van der Waals radii, with the result that the structure is based on ribbons and not layers. The structure partitions into one set of regions at $c=0,1 \ldots$ etc., where the ribbons run parallel to [110], and a second set through the middle of the unit cell $(c=0.5)$, where the ribbons run parallel to [110] (Fig. 5b). The overall effect is to interleave morpholine molecules. The angle between the mean planes of morpholine molecules in neighbouring ribbons passing along [110] and [110] is $78.4(4)^{\circ}$ and the closest contacts made by

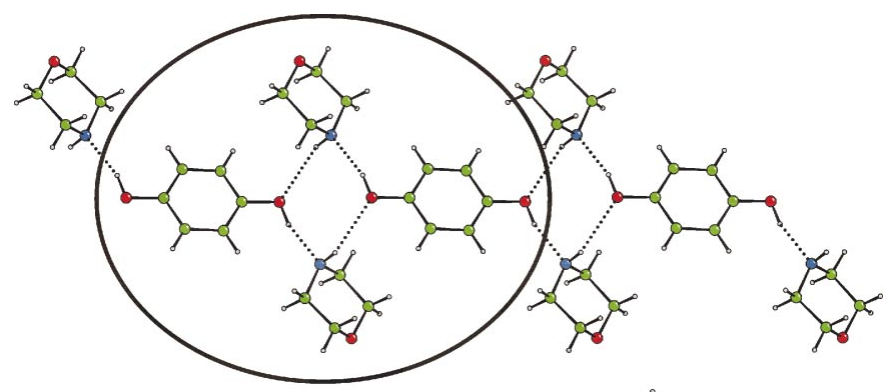

(a)

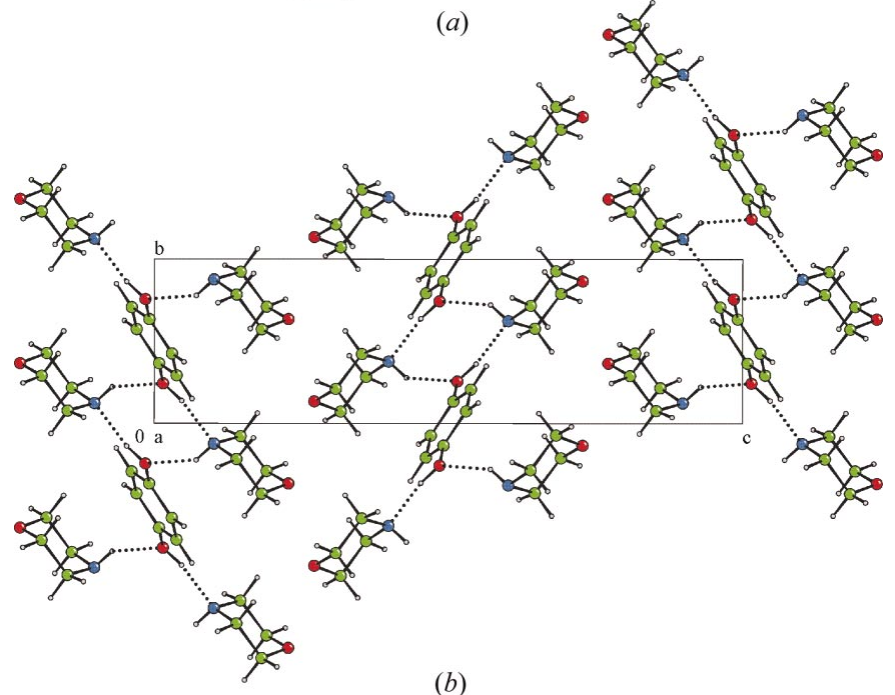

Figure 5

(a) Quinol-morpholine (1/2) (3) ribbon viewed perpendicular to the (112) planes. The ribbon does not extend into layers because of the relatively weak acceptor ability of the ether oxygen, which does not take part in hydrogen bonding. (b) The structure of quinol-morpholine $(1 / 2)$ (3) viewed down the $a$ axis showing the interleaved morpholine molecules. The ribbons at $c=0,1 \ldots$ etc. run parallel to [110] and the second set of ribbons at $c=0.5$ run parallel to [110]. 
$\mathrm{O} 4 S$ are to $\mathrm{H}$ atoms attached to $\mathrm{C} 2 \mathrm{~S}$ and $\mathrm{C} 3 S(2.75$ and $2.81 \AA$, respectively)

\subsection{Quinol-pyridine (1/2) (4)}

Pyridine is related to pyrazine through the substitution of one of the $\mathrm{N}$ atoms by $\mathrm{CH}$. This co-crystal crystallizes with one molecule of pyridine and a half molecule of quinol in the asymmetric unit. The quinol molecule resides on a crystallographic inversion centre. The stoichiometry of this co-crystal is 1:2, although we have recently shown that quinol also forms a 1:1 co-crystal with pyridine (Oswald, Motherwell \& Parsons, 2004).

The hydrogen-bonding activity in the quinol molecules is identical to that observed in the pyrazine co-crystal (see above and Fig. 3). The quinol donates to two symmetrically equivalent pyridine molecules through $\mathrm{OH} \cdots \mathrm{N}$ interactions (Fig. 6a) to form a discrete $D_{2}^{2}(10)$ motif consisting of one quinol and two pyridine molecules. This is analogous to the structure of the morpholine co-crystal, with the $\mathrm{CH}$ group in the 4-position of the pyridine acting as a chain-stopper and, as a result, this
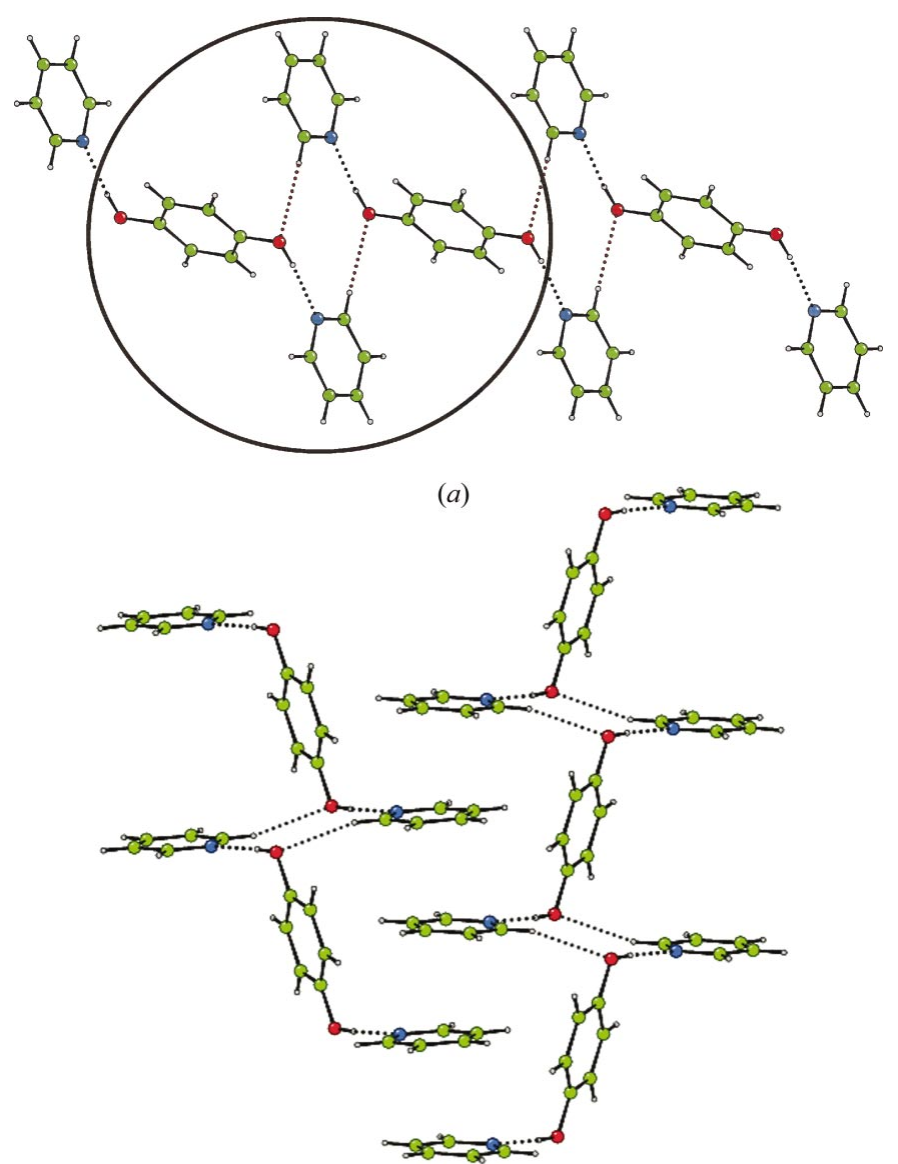

(b)

\section{Figure 6}

(a) Quinol-pyridine (1/2) (4) structure viewed perpendicular to the (212) planes. The doubly bridging motif gives a $R_{4}^{4}(10)$ graph set (cf. pyrazine, circled). (b) Quinol-pyridine (1/2) (4) viewed down the $a$ axis. Colour scheme: $\mathrm{C}$ green, $\mathrm{H}$ grey, $\mathrm{O}$ red and $\mathrm{N}$ blue. The $\pi$-stacking of pyridine molecules from neighbouring ribbons can clearly be seen. structure consists of ribbons. The $\mathrm{CH}$ adjacent to the $\mathrm{N}$ atom of a pyridine in a neighbouring quinol-pyridine (1/2) unit acts as the donor group to the phenolic oxygen, yielding the same doubly bridging $R_{4}^{4}(10)$ motif as observed in the pyrazine cocrystal (Fig. 6a). Neighbouring ribbons interact with each other through $\pi$-stacking of the pyridine molecules in which the stacking distance is $3.45 \AA$ and the angle between the mean planes of stacked pyridine molecules is $5.32(6)^{\circ}$ (Fig. $6 b)$.

\subsection{Quinol-piperidine (1/2) (5)}

Piperidine is related to morpholine through the substitution of the $\mathrm{O}$ atom with a methylene group. This co-crystal crystallizes with one molecule of piperidine and half a molecule of quinol in the asymmetric unit ( $c f$. the morpholine and pyridine co-crystals). The quinol resides on a crystallographic inversion centre. The $\mathrm{H}$ atom $(\mathrm{H} 1 S)$ attached to the nitrogen in the piperidine molecule was located in a difference-Fourier map and occupies the axial position.

This co-crystal forms a similar structure to morpholine and pyridine in that it consists of discrete $D_{2}^{2}(10)$ units, consisting of one quinol and two piperidine molecules, which are linked into a ribbon via $\mathrm{NH}$... O hydrogen bonds. Rather than forming an $R_{2}^{2}(8)$ motif the doubly bridging subunit forms an $R_{4}^{4}(18)$ graph set (Fig. $7 a$, see also Table 2). There are a larger number of atoms in this graph-set descriptor than in the structures discussed previously, because of the difference in the relative orientations of the quinol and piperidine molecules: $c f$., for example, Figs. $4,6(a)$ and $7(a)$. A view of the packing along the direction of the ribbons ([010]) is shown in Fig. 7(b).

\subsection{Quinol-(4,4'-bipyridine) (1/2) (6)}

Co-crystals of quinol with 4,4'-bipyridine, $N$-methylmorpholine and $N, N^{\prime}$-dimethylpiperazine were studied in order to investigate the effect of steric hindrance on the doubly bridging motif that has been observed in all the structures described so far. Like morpholine, $4,4^{\prime}$-bipyridine forms a 1:2 co-crystal with quinol, and the asymmetric unit contains half a molecule of quinol and one molecule of 4,4'-bipyridine. The angle between the $\mathrm{C}_{5} \mathrm{~N}$ planes in the $4,4^{\prime}$-bipyridine molecules is $28.59(6)^{\circ}$.

Predictably, the quinol interacts with the 4,4'-bipyridine molecule through the hydrogen bond between $\mathrm{O} 1 A$ and $\mathrm{N} 1 B$. In terms of the symmetry of its hydrogen-bond acceptor functions bipyridine resembles dioxane, pyrazine and piperazine. An attempt was made to obtain a 1:1 co-crystal by recrystallization of a stoichiometric mixture of the components from acetone. This procedure has been used for the preparation of a 1:1 co-crystal of quinol and 4,4'-(bipyridyl)ethane, but in the case of $4,4^{\prime}$-bipyridine the same $1: 2$ cocrystal was obtained as from ethanol.

As in the other 1:2 co-crystals in this series, the structure contains a $D_{2}^{2}(10)$ unit consisting of one quinol and two bipyridine molecules. These are then linked into ribbons via a subunit (Fig. 8a) in which two quinol molecules are doubly 
bridged by $\mathrm{CH}$... O interactions with two bipyridine molecules. The $\mathrm{C}-\mathrm{H}$ groups adjacent to the $\mathrm{N}$ atoms in bipyridine sometimes act as donors. This is not at all uncommon and it has even been used in crystal structure design, but it is not observed here. Instead, the quinol $\mathrm{O}$ atom acts as an acceptor for the $\mathrm{H}$ atom adjacent to the central $\mathrm{C}-\mathrm{C}$ bond of the bipyridine $\left(\mathrm{C} 9 S-\mathrm{H} 9 \mathrm{~S} \ldots \mathrm{O} 1 \mathrm{~A}, 2.46 \AA\right.$ А $\left.169^{\circ}\right)$.

A second $\mathrm{CH} \cdots \mathrm{O}$ bond exists between $\mathrm{C} 5 S-\mathrm{H} 5 S$ and $\mathrm{O} 1 A$ $\left(2.59 \AA, 152^{\circ}\right)$ that connects the ribbons together to form

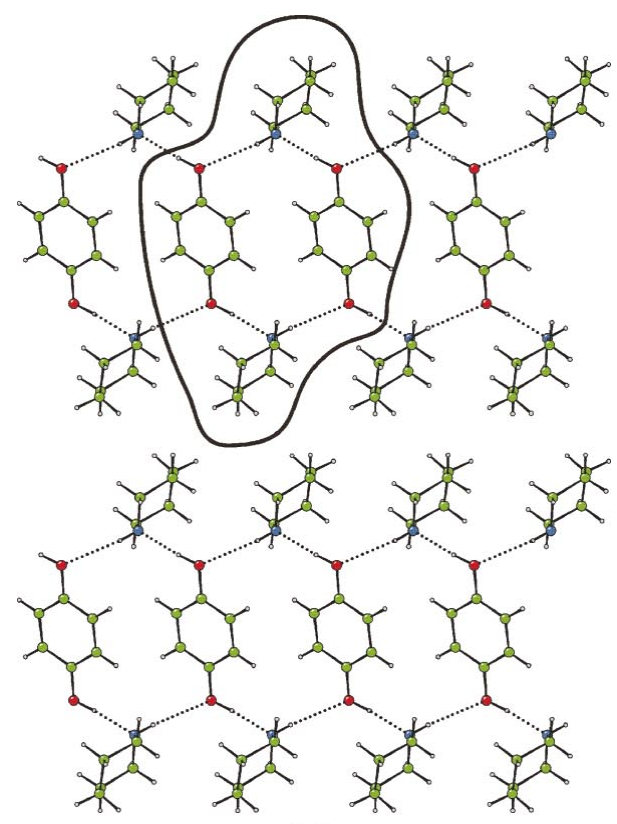

(a)

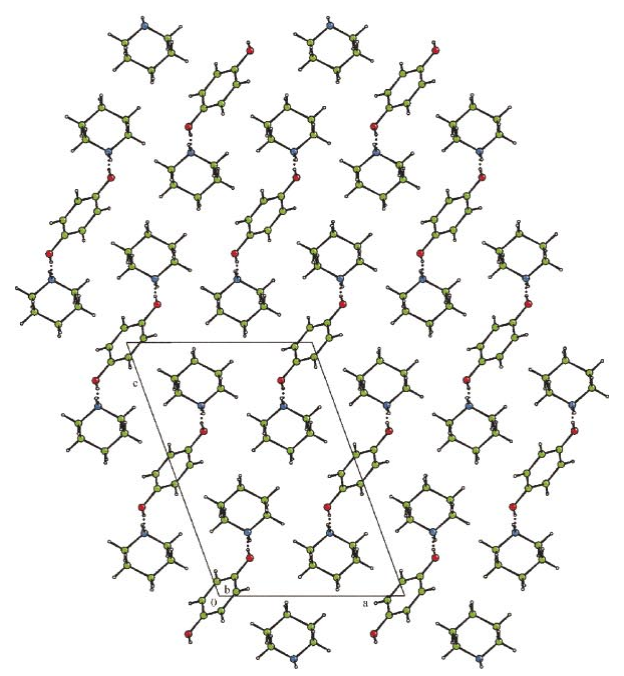

(b)

Figure 7

(a) Quinol-piperidine (1/2) (5) viewed perpendicular to the (101) planes. Ribbons are formed rather than an extended layer motif, which follows from the absence of strong hydrogen-bonding functions in the 4-position in piperidine. (b) Quinol-piperidine (1/2) (5) viewed down the $b$ axis. Colour scheme: $\mathrm{C}$ green, $\mathrm{H}$ grey, $\mathrm{O}$ red and $\mathrm{N}$ blue. The structure is based on ribbons which form along the [010] direction and are arranged in the $(\overline{2} 02)$ planes. Piperidine molecules in neighbouring chains occupying the same (202) plane are interleaved. layers. When viewed along the $b$ axis the structure consists of regions of quinol molecules occupying different layers at $c=0$, 1 ...etc. and regions of bipyridine molecules at $c=\frac{1}{2}$ in which bipyridine molecules in different layers interleave (Fig. $8 b$ ). The pyridine moieties based on N7S are involved in offset stacks disposed about inversion centres, in which the distance between the ring planes is $3.62 \AA$ with an offset of $1.77 \AA$ (Hunter et al., 2001). The layers are additionally connected by weak $\mathrm{N} \cdot \cdot \mathrm{H}$ interactions measuring 2.9-3.0 $⿱$ A, involving N7S in one layer and $\mathrm{H}$ atoms in another (these contacts are not shown in Fig. $8 b$ for the sake of clarity).

\subsection{Quinol-N-methylmorpholine (1/2) (7)}

Crystals of $N$-methylmorpholine were grown by Boese's laser-assisted zone refinement method from a 1:2 mixture of quinol and $N$-methylmorpholine held in a capillary mounted on the diffractometer. Crystal growth experiments by more conventional procedures failed to yield anything but crystals of quinol.

The crystal structure contains half a molecule of quinol and a whole molecule of $N$-methylmorpholine in the asymmetric unit. The methyl group of the $N$-methylmorpholine molecule adopts the expected equatorial position, and bond distances and angles are normal. As in the other 1:2 co-crystals there is a $D_{2}^{2}(10)$ motif consisting of one quinol and two $N$-methylmor-

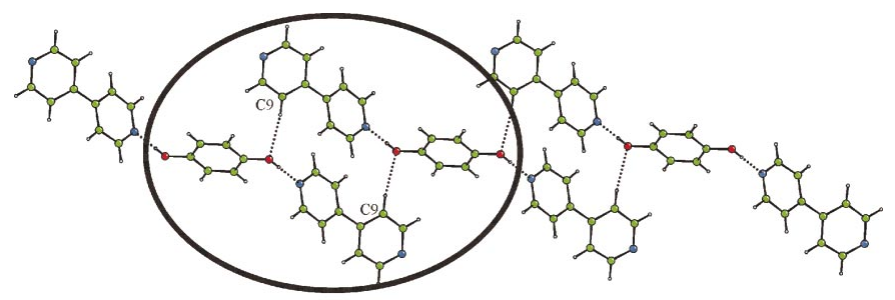

(a)

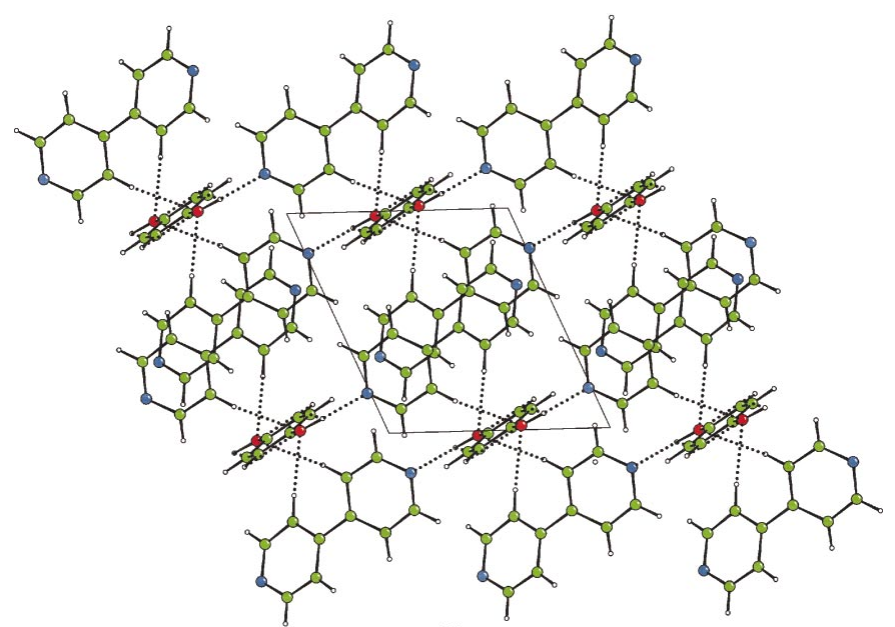

(b)

Figure 8

(a) Quinol-(4,4'-bipyridine) (1/2) (6) viewed perpendicular to the $(11 \overline{2})$ planes. The graph set for this motif is the same as the piperidine structure, $R_{4}^{4}(18)$ (circled). (b) Quinol-(4,4'-bipyridine) (1/2) (6) viewed perpendicular to the $b$ axis showing the interleaving between layers. Colour scheme: $\mathrm{C}$ green, $\mathrm{H}$ grey, $\mathrm{O}$ red and $\mathrm{N}$ blue. The different regions of quinol molecules at $c=0,1 \ldots$ etc. and bipyridine molecules at $c=\frac{1}{2}$. 
pholine molecules connected by centrosymmetrically related $\mathrm{OH} \cdots \mathrm{N}$ hydrogen bonds (Fig. 9). In the morpholine co-crystal (see above) the $D_{2}^{2}(10)$ units were linked together via a doubly bridging subunit involving $\mathrm{NH}$... O interactions, but substitution of the $\mathrm{NH}$ group by $\mathrm{N}\left(\mathrm{CH}_{3}\right)$ means that this type of bridging cannot occur in the $N$-methylmorpholine co-crystal. The steric bulk of the methyl group also forces a change in the relative orientation of the quinol and guest molecules, preventing the alternative $\mathrm{O} \cdots \mathrm{CH}$ (ring) interaction seen elsewhere in this series. The steric effect of the $N$-methyl group has therefore been to disrupt the formation of the doubly bridging unit highlighted in Figs. 2-8. $D_{2}^{2}(10)$ units are instead linked via $\mathrm{CH}_{3} \ldots \mathrm{O}$ interactions between $N$-methylmorpholine molecules, forming ribbons. The ribbons are then linked into a layer by further $\mathrm{CH} \cdots \mathrm{O}$ interactions between $\mathrm{N}$ methylmorpholine molecules.

\subsection{Quinol- $N, N^{\prime}$-dimethylpiperazine (1/1) (8)}

In the asymmetric unit of the dimethylpiperazine co-crystal there are two molecules of quinol and four half-molecules of dimethylpiperazine, so that the co-crystal has overall 1:1 stoichiometry. In all cases the methyl groups of the dimethylpiperazine are in the expected equatorial positions.

The strongest intermolecular interactions are $\mathrm{OH} \cdots \mathrm{N}$ hydrogen bonds which build up $C_{2}^{2}(12)$ chains (Fig. 10), similar to those observed in the quinol-piperazine (1/1) co-crystal. There are two symmetrically inequivalent chains present in the structure, both involving one quinol molecule and two independent guest molecules. The quinol is present in a noncentrosymmetric conformer, which results in the chains

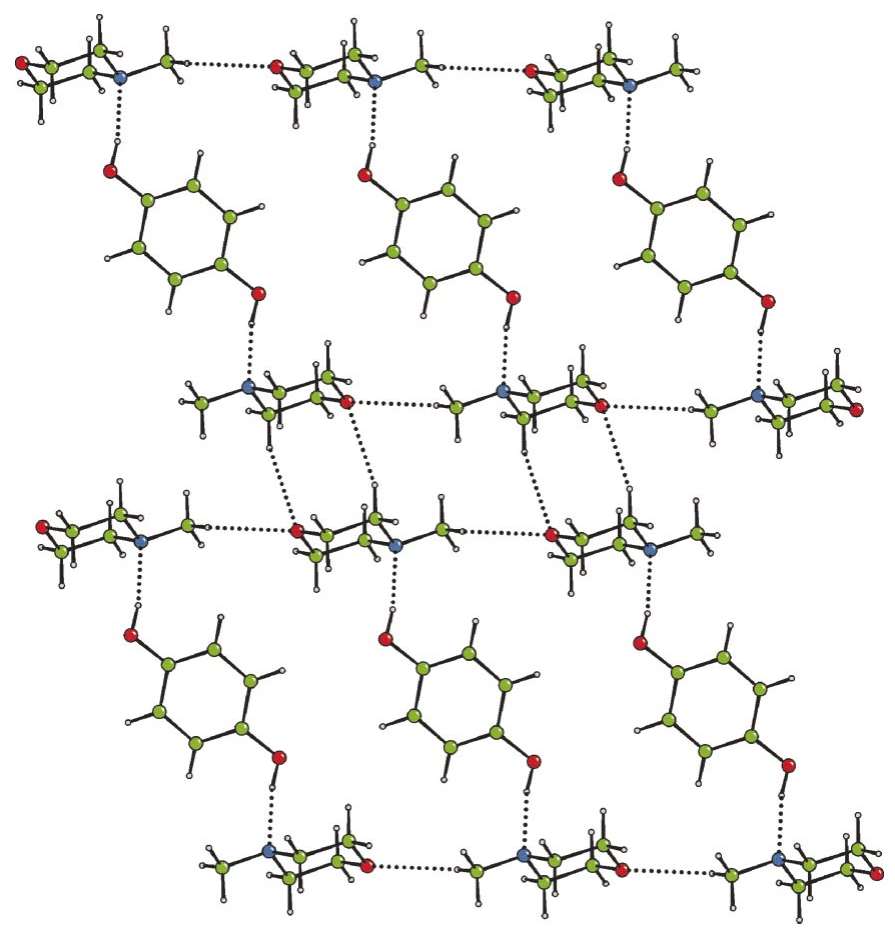

Figure 9

Quinol- $N$-methylmorpholine (1/2) (7) viewed perpendicular to the (101) planes. becoming more sinusoidal than in the piperazine co-crystal. As in the $N$-methylmorpholine co-crystal described above, the $\mathrm{N}$-methyl groups prevent the formation of bridging interactions between chains, which are instead linked by $\mathrm{CH} \cdots \mathrm{O}$ interactions with other chains that pass through the rather open structure depicted in Fig. 10.

\section{Discussion and conclusions}

\subsection{Hydrogen-bond formation in co-crystals of quinol}

Our previous paper on paracetamol co-crystals utilized the Cambridge Structural Database (CSD) in rationalizing the formation of a series of co-crystals from pure paracetamol (Oswald et al., 2002; Oswald, Motherwell, Parsons, Pidcock \& Pulham, 2004) and a similar procedure can be used for this series of compounds. There are only two classical hydrogenbond donor groups in this series: the phenol $\mathrm{OH}$ and a secondary amine $\mathrm{NH}$. The aromatic or aliphatic $\mathrm{CH}$ groups adjacent to the heteroatom with the phenolic oxygen can also act as donors. The acceptor groups in the series are a phenolic $\mathrm{O}$, secondary or tertiary amine $\mathrm{N}$, ether $\mathrm{O}$ and pyridine $\mathrm{N}$. The results of searches of the CSD for typical hydrogen-bond geometries involving these functionalities are listed in Table 3; searching criteria are given in the legend to that table.

In interpreting the data in Table 3 we assume that the strength of hydrogen bonds is related to the donor-hydrogenacceptor distance with the $D-\mathrm{H}$ bond normalized to typical neutron distances $(\mathrm{O}-\mathrm{H} \quad 0.983, \mathrm{~N}-\mathrm{H} 1.009$ and $\mathrm{C}-\mathrm{H}$ $1.083 \AA$ ). Amine $\mathrm{N}$ atoms are more strongly basic than phenolic or ether $\mathrm{O}$ atoms, and the strongest bonds in Table 3 are those from a phenol donor to a secondary or tertiary amine, or a pyridine N. In co-crystals of this type hydrogen bonds are formed to the guest rather than to the weaker $\mathrm{OH} \cdots \mathrm{O}(\mathrm{H})$ found in pure quinol, and where $\mathrm{N}$ atoms are present in the 1 and 4 positions of the guest (i.e. in pyrazine, piperazine and $N, N^{\prime}$-dimethylpiperazine), 1:1 co-crystals are formed. Hydrogen bonds in which the phenolic and ether $\mathrm{O}$ atoms act as acceptors to weak $\mathrm{CH}$ donors are similar in strength. This observation helps to rationalize the formation of the dioxane co-crystal. It was formed from a solution of quinol in dioxane that was allowed to evaporate at room

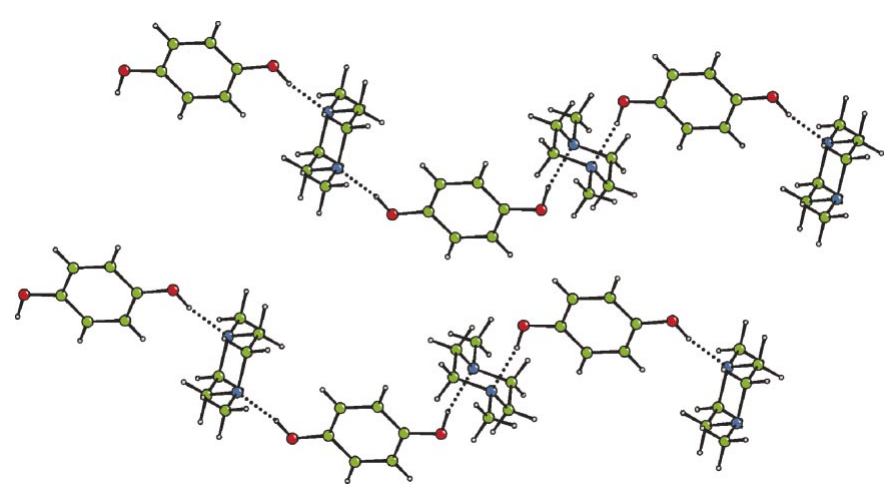

Figure 10

Quinol- $N, N^{\prime}$-dimethylpiperazine (1/1) (8). The inequivalent chains run perpendicular to these chains filling the space between the two chains. 
temperature. Under these conditions there is excess dioxane present in the system, which would favour the $\mathrm{OH} \cdots \mathrm{O}$ (ether) interaction, leading to a 1:1 co-crystal of quinol and dioxane.

In the co-crystals of quinol with molecules with $\mathrm{N}, \mathrm{NH}$ or $\mathrm{NMe}$ and $\mathrm{O}, \mathrm{CH}$ or $\mathrm{CH}_{2}$, respectively, in the 1 and 4 positions, the quinol hydrogen bonds exclusively to the nitrogen moiety. In the case of morpholine and $N$-methylmorpholine the ether $\mathrm{O}$ atom is a much less effective acceptor than the amine nitrogen (Table 3); in piperidine and pyridine the $\mathrm{CH}_{2}$ and $\mathrm{CH}$ groups in the 4-positions can, of course, fail to act as acceptors at all. Quinol selectively binds to the nitrogen group and, in order to satisfy the hydrogen-bonding capacity of quinol, all four of these co-crystals crystallize in a 1:2 quinol-to-guest ratio.

\subsection{The co-crystal of quinol with $4,4^{\prime}$-bipyridine}

Considerations of hydrogen-bonding strength based on the data in Table 3 enable the stoichiometries of the majority of co-crystals studied here to be rationalized. The exception is the co-crystal of quinol with 4,4'-bipyridine, which would be predicted to form a 1:1 co-crystal, whereas the observed stoichiometry is $1: 2$, with only one of the two $\mathrm{N}$ atoms in each bipyridine molecule being used in hydrogen bonding. An attempt to obtain a 1:1 co-crystal under the same conditions as employed in the synthesis of quinol-1,2-bis(4-pyridyl)ethane (Corradi et al., 2000) was not successful. It is possible that a substantial change of crystallization conditions (e.g. solvothermal methods or high pressure) would lead to substantially different behaviour: paracetamol, for example, forms a methanol solvate which can be prepared at $0.62 \mathrm{GPa}$, but undergoes desolvation at ambient pressure (Fabbiani et al., 2003). It is possible that the anomalous behaviour of 4,4'bipyridine occurs as a result of competition between hydrogen bonding (leading to a 1:1 co-crystal) and $\pi$-stacking (leading to a 1:2 co-crystal).

Pyrazine is similar to $4,4^{\prime}$-bipyridine in that it contains two aromatic $\mathrm{N}$-acceptor sites, yet this forms a 1:1 co-crystal with quinol; pyrazine ( $\mathrm{p} K_{a} 0.6$ ) is also less basic than $4,4^{\prime}$-bipyridine ( $\mathrm{p} K_{a}$ 4.8). This trend is observed in other co-crystals: a search of the CSD reveals that pyrazine always acts as a double acceptor for hydroxyl-containing moieties, whereas for 4,4'bipyidine both $\pi$-stacking and hydrogen-bonding interactions are observed. Theoretical values of the polarizabilities of neutral and protonated versions of pyridine and pyrazine have recently been published (Soscùn et al., 2004) and values (in a.u.) are: pyridine, 61.14 ; pyridine- $\mathrm{H}^{+}, 54.30$; pyrazine, 56.38 ; pyrazine- $\mathrm{H}^{+}, 50.67$. The non-hydrogen-bonded ring of $4,4^{\prime}-$ bipyridine in the co-crystal with quinol plausibly has a polarizability similar to pyridine (61.14 a.u.), whereas a singly coordinated pyrazine ring would have a polarizability somewhere between 56.38 and 50.57 a.u. The higher polarizability of the former would tend to promote $\pi$-stacking. This may be enough to make this interaction competitive with hydrogen bonding for 4,4'-bipyridine.

We have recently shown that quinol forms a 1:1 co-crystal with pyridine (Oswald, Motherwell \& Parsons, 2004), whereas a 1:2 co-crystal would normally have been anticipated. The formation of this co-crystal could also be ascribed to competition between hydrogen bonding with a combination of $\mathrm{CH} \cdots \mathrm{O}, \mathrm{CH} \cdots \pi$ and $\pi$-stacking.

\subsection{Hydrogen-bonding patterns}

All the 1:1 co-crystals described here are based on $C_{2}^{2}(12)$ chains of alternating quinol and guest molecules. All the 1:2 co-crystals are based on discrete $D_{2}^{2}(10)$ motifs containing one quinol and two guest molecules. In all but the two sterically hindered cases $\left(N\right.$-methylmorpholine and $N, N^{\prime}$-dimethylpiperazine) the $C_{2}^{2}(12)$ chains or $D_{2}^{2}(10)$-based motifs are linked about an inversion centre by $\mathrm{NH} \cdots \mathrm{O}$ or $\mathrm{CH} \cdots \mathrm{O}$ interactions in which quinol molecules are doubly bridged by pairs of guest molecules. This linking of chains builds layers in the 1:1 cocrystals; linking of the discrete units in the 1:2 co-crystals builds ribbons.

These observations also apply to the crystal structure of quinol itself. Three polymorphs of quinol are known, but the simplest is the monoclinic $\gamma$-polymorph, and the co-crystals discussed in this paper are related to this structure. In the asymmetric unit there are two half molecules of quinol residing on inversion centres. The primary graph set is $C_{2}^{2}(14)$ formed by $\mathrm{OH} \cdots \mathrm{O}(\mathrm{H})$ hydrogen bonds; this corresponds to the $C_{2}^{2}(12)$ chains of the 1:1 co-crystals described above. These chains are parallel to one another and hydrogen bond together to form a doubly bridging $R_{4}^{4}(18)$ graph set at the secondary level (Fig. 11).

\subsection{Co-crystals of resorcinol and catechol}

Co-crystal formation by the isomers of quinol, resorcinol (1,3-dihyroxybenzene) and catechol (1,2-dihydroxybenzene)

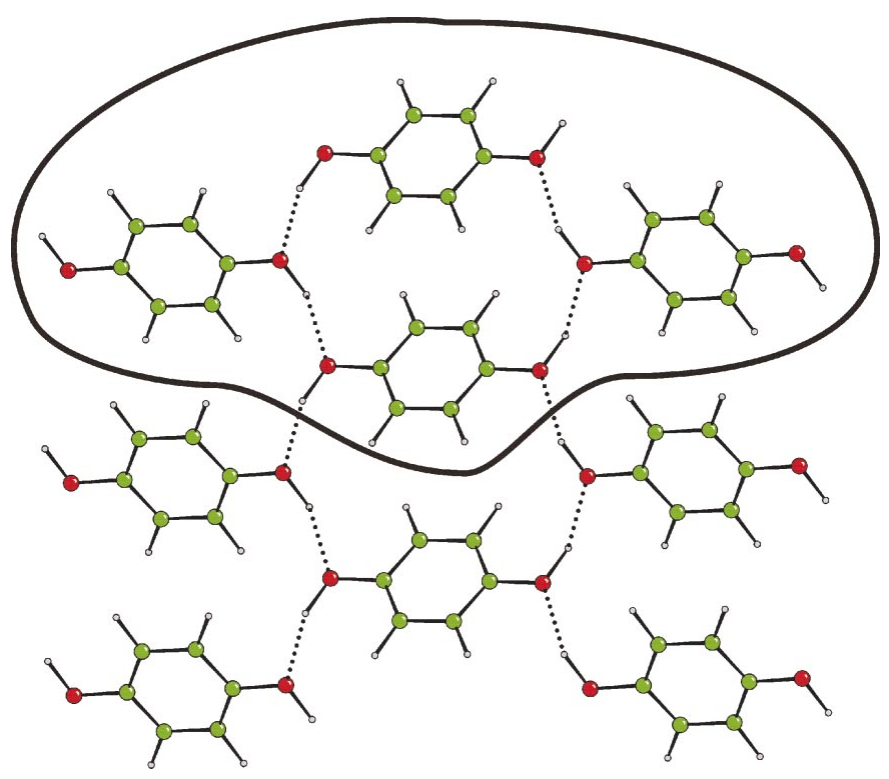

Figure 11

$\gamma$-Quinol viewed down the $a$ axis. $\gamma$-Quinol is a layered structure where the primary graph set is $C_{2}^{2}(14)$; these chains are parallel to one another and hydrogen bond together to form an $R_{4}^{4}(18)$ graph set. 
has been more lightly investigated than those of quinol itself. There have been no systematic studies of the type presented here for quinol for either compound, although we are currently investigating the formation of such compounds.

There are 13 chemically distinct co-crystals of resorcinol in Version 5.25 of the CSD. Seven of these form hydrogenbonded chains similar to those observed for quinol (for example, CSD refcodes ACOYOG and VAKTUX). The nonlinear arrangement of the $\mathrm{OH}$ donor sites in resorcinol also allows resorcinol to build discrete hydrogen-bonded clusters rather than infinite motifs (e.g. refcodes ABEKUN and TAHVII). This feature has found application in forming clusters in which $\mathrm{C}=\mathrm{C}$ bonds are bought into close proximity so that 2+2-cycloadditions occur on UV irradiation (MacGillivray et al., 2000). Resorcinol itself (RESORA03) forms a three-dimensional network based on rings of molecules. Similar remarks apply to co-crystals of catechol. The crystal structure of catechol itself contains hydrogen-bonded dimers and these are linked, pairwise, into chains. Clusters of varying sizes are observed in eight out of 16 co-crystals in the CSD; chain motifs account for most of the remainder.

\subsection{Inversion symmetry in quinol co-crystals}

In all but one co-crystal described here (8) the quinol is present in its centrosymmetric conformer. This preference is reflected in other quinol co-crystals in the CSD; out of 108 structures only seven have quinol in the non-centrosymmetric form (CABWAD, COBMOV, GUSSES, IDUMUP, KEFBEC, QUNNEC, SUWGOG); there does not appear to be any common feature in these structures that might have explained the adoption of the less usual conformation. It is possible that the adoption by quinol of its centrosymmetric conformer is related to the general preference for centrosymmetric packing in crystal structures. In fact, quinol has a tendency to occupy crystallographic inversion centres in its co-crystals: of the 71 quinol molecules in the relational database CSD symmetry (Yao et al., 2002; this was built using version 5.19 of the CSD), 46 occupy Wyckoff positions $\overline{1}$. This is consistent with the behaviour of centrosymmetric molecules in general. In a recent survey Pidcock et al. (2003) showed that molecules with an inversion centre retain this symmetry element in their crystal structures in over $80 \%$ of cases. This bias towards centrosymmetry is related to the promotion of dense packing by crystallographic inversion centres. Similar features are observed in the retention in crystal structures of other 'pointacting' symmetry elements 3 and 4 (Pidcock et al., 2003).

We thank the EPSRC, the Cambridge Crystallographic Data Centre and the University of Edinburgh for funding. We also thank the referees for their careful reading of the draft manuscript.

\section{References}

Allen, F. H. \& Motherwell, W. D. S. (2002). Acta Cryst. B58, 407422.

Barnes, J. C., Paton, J. D. \& Blyth, C. S. (1990). Acta Cryst. C46, $1183-$ 1184.

Bernstein, J., Davis, R. E., Shimoni, L. \& Chang, N.-L. (1995). Angew. Chem. Int. Ed. Engl. 34, 1555-1573.

Blessing, R. H. (1995). Acta Cryst. A51, 33-38.

Boese, R. \& Nussbaumer, M. (1994). Correlations, Transformations, and Interactions in Organic Crystal Chemistry, edited by D. W. Jones \& A. Katrusiak, Vol. 7, pp. 20-37. IUCr Crystallographic Symposia 7. IUCr and Oxford University Press.

Bolte, M. \& Lerner, H.-W. (2001). Private Communication to CSD, CCDC 161816.

Bruno, I. J., Cole, J. C., Edgington, P. R., Kessler, M., Macrae, C. F., McCabe, P., Pearson, J. \& Taylor, R. (2002). Acta Cryst. B58, 389397.

Buschmann, J., Müller, E. \& Luger, P. (1986). Acta Cryst. C42, 873876.

Caspari, W. A. (1926). J. Chem. Soc. pp. 2944-2948.

Caspari, W. A. (1927). J. Chem. Soc. pp. 1093-1095.

Corradi, E., Meille, S. V., Messina, M. T., Metrangolo, P. \& Resnati, G. (2000). Angew. Chem. Int. Ed. 39, 1782-1786.

Cosier, J. \& Glazer, A. M. (1986). J. Appl. Cryst. 19, 105107.

Fabbiani, F. P. A., Allan, D. R., Dawson, A., David, W. I. F., McGregor, P. A., Oswald, I. D. H., Parsons, S. \& Pulham, C. R. (2003). Chem. Commun. pp. 3004-3005.

Farrugia, L. J. (1999). J. Appl. Cryst. 32, 837-838.

Hunter, C. A., Lawson, K. R., Perkins, J. \& Urch, C. J. (2001). J. Chem. Soc. Perkin Trans. 2, pp. 651-669.

Lindeman, S. V., Shklover, V. E. \& Struchkov, Yu. T. (1981). Cryst. Struct. Commun. 10, 1173-1179.

Maartmann-Moe, K. (1966). Acta Cryst. 21, 979-982.

MacGillivray, L. R., Reid, J. \&. Ripmeester, J. A. (2000). J. Am. Chem. Soc. 122, 7817-7818.

Motherwell, W. D. S., Shields, G. P. \& Allen, F. H. (1999). Acta Cryst. B55, 1044-1056.

Oswald, I. D. H., Allan, D. R., McGregor, P. A., Motherwell, W. D. S., Parsons, S. \& Pulham, C. R. (2002). Acta Cryst. B58, 10571066.

Oswald, I. D. H., Motherwell, W. D. S. \& Parsons, S. (2004). Acta Cryst. E60, o1967-o1969.

Oswald, I. D. H., Motherwell, W. D. S., Parsons, S., Pidcock, E. \& Pulham, C. R. (2004). Cryst. Rev. 10, 57-66.

Parkin, A., Oswald, I. D. H. \& Parsons, S. (2004). Acta Cryst. B60, 219-227.

Pidcock, E., Motherwell, W. D. S. \& Cole, J. C. (2003). Acta Cryst. B59, 634-640.

Sheldrick, G. M. (1997a). SADABS. Bruker-AXS, Madison, Wisconsin, USA.

Sheldrick, G. M. (1997b). SHELXTL. Bruker-AXS, Madison, Wisconsin, USA.

Soscùn, H., Bermúdez, Y., Castellano, O. \& Hernández, J. (2004). Chem. Phys. Lett. 396, 117-121.

Spek, A. L. (2002). PLATON. Utrecht University, The Netherlands.

Taylor, R. \& Macrae, C. F. (2001). Acta Cryst. B57, 815827.

Watkin, D. J., Pearce, L. \& Prout, C. K. (1993). CAMERON. Chemical Crystallography Laboratory, University of Oxford, England.

Yao, J. W., Cole, J. C., Pidcock, E., Allen, F. H., Howard, J. A. K. \& Motherwell, W. D. S. (2002). Acta Cryst. B58, 640-646. 